\title{
Some biochemical characteristics of species of the genus Monarda
}

\author{
Anastasia Petruk $^{1 *}$, Irina Lobanova ${ }^{1}$, and Elisaveta Bolotnik $^{2}$ \\ ${ }^{1}$ Central Siberian Botanical Garden, SB RAS, 630090 Novosibirsk, Russia \\ ${ }^{2}$ Botanical Garden, UB RAS, 620144 Ekaterinburg, Russia
}

\begin{abstract}
The paper presents a comparative study of the content and composition of biologically active substances of the aboveground parts of plants of some Monarda species cultivated in the Botanical Garden, Ural Branch of Russian Academy of Sciences, Ekaterinburg. The greatest quantity of flavones, tannins were found in M. citriodora Cerv. ex Lag., carotenoids, pectins, saponins - in M. fistulosa L., pectins - in M. didyma L., protopectins - in M. media Will. The component composition of the phenolic complex of the samples was studied by high-performance liquid chromatography on an analytical HPLC-system Agilent $1200.70 \%$ ethanol extracts of plants of Monarda species contained at least 35 compounds of phenolic nature, including flavones luteolin, luteolin 7-glucoside, chlorogenic acid.
\end{abstract}

\section{Introduction}

The genus Monarda L. from the Lamiaceae family has up to 100 species. The homeland of representatives of this genus of North America. Under cultural conditions, species of the genus Monarda are grown in many countries of Eurasia and America. They are used as aromatic, ornamental, and medicinal plants [1-3]. Plants to $150 \mathrm{~cm}$ tall. Flowers are collected in inflorescences to $7 \mathrm{~cm}$ in diameter. The flowering of one inflorescence lasts 18 20 days. Most species of the genus Monarda grow in dry areas [3].

Interest in the species of the genus Monarda only increases over time. Numerous research results have proven the economic value and practical importance of species of this genus. The phenolic complex of plants of the genus has been partially investigated. Essential oils have been studied in detail. Flavonoids are effective against various pathogens [2]. Essential oil and extracts of Monarda have high bactericidal, antiviral, antifungal, antimycoplasma and anthelmintic activity, immunomodulatory effect, antioxidant, radioprotective, anti-sclerotic, desensitizing, anti-cancer, anti-inflammatory, analgesic effects. They have a sedative effect on the central nervous system. Flavonoids stimulate the regeneration of damaged skin, reduce to normal the increased lipid metabolism $[2,3]$.

The aim of the work is a comparative study of the composition and content of biologically active substances and antitoxic properties of the above-ground part of Monarda

*Correspondingauthor:pet.a@mail.ru 
plants cultivated in the botanical garden of the Ural Branch of the Russian Academy of Sciences, Ekaterinburg.

\section{Materials and methods}

Five species of the genus Monarda were studied - four species of the first year of life M. didyma, M. citriodora, M. fistulosa, and M. media (collection 2019) and one species of M. menthaifolia of the second and third year of life (collection 2018, 2019). The object of the study is the above-ground part of vegetative and flowering plants, collected in the Botanical Garden of Ural Branch of RAS (Sverdlovsk Region, Ekaterinburg). The raw material was dried in well-ventilated rooms, crushed to a particle size of $2 \mathrm{~mm}$, mixed and a medium sample was taken.

To extract phenolic compounds, double extraction with $70 \%$ ethanol in a water bath was performed. The quantitative content of flavones, tannins, carotenoids, and catechins was determined by the spectrophotometric method on spectrophotometer SF-56 [4-8].

The quantitative content of pectin substances was determined by the calibration curve constructed by galacturonic acid. The density of stained solutions was measured on spectrophotometer Agilent 8453 SF [9]. Saponins were determined by the weight method [10].

The component composition of the phenolic complex of the samples was studied by high-performance liquid chromatography on an analytical HPLC system consisting of an Agilent 1200 liquid chromatograph. The chromatographic separation was conducted at $25^{\circ} \mathrm{C}$ on a Zorbax SB-C18 Column $(4.6 \times 150 \mathrm{~mm}, 5 \mu \mathrm{m}$ internal diameter $)$ with the Agilent Guard Column Hardware Kit. Detection was performed at a wavelength of $\lambda=360$ $\mathrm{nm}$ [11]. Retention times of compounds peaks on chromatograms of analyzed samples were compared with retention times of peaks of standard samples and their UV spectra.

\section{Results}

The greatest quantity of flavones $(4.26 \%)$ and tannins $(20.65 \%)$ was found in $\mathrm{M}$. citriodora Cerv. ex Lag., carotenoids (184.07\%), pectins $(1.84 \%)$ and saponins $(15.38 \%)$ in M. fistulosa L., pectins (1.84 \%) - in M. didyma L., protopectins (12.22 \%) - in M. media Willd. M. menthaifolia in the phase of mass flowering is distinguished by the increased content of catechins $-0.35 \%$ (Table 1 ).

The least amount of flavones $(2.25 \%)$, carotenoids $(87.88 \%)$ and tannins $(13.39 \%)$ is typical for M. media, catechins $(0.12 \%)$ - for M. fistulosa, saponins $(1.86 \%)$ and pectins $(0.74 \%)$ - M. menthaifolia (flowering, 2nd year of life, 2018), protopectins (8.14\%) Monarda didyma . (Table 1). 3,90\% flavones, 14,68 \% tannins, 0,26\% catechins, $0,97 \%$ pectins, $8,62 \%$ protopectins, $102,73 \%$ carotenoids, $7,18 \%$ saponins were found in the above-ground parts of M. menthaefolia plants (from the air-dry mass of raw materials).

The component composition of the phenolic complex of the samples was studied by high-performance liquid chromatography. $70 \%$ ethanol extracts of the aboveground parts of all studied plants of Monarda species contained at least 35 compounds of phenolic nature, of which flavones luteolin, luteolin 7-glucoside, and chlorogenic acid were identified. The results obtained can be useful in developing practical recommendations for the collection of medicinal plants in different periods of vegetation.

Table 1. Biologically active substances of some species of the genus Monarda (in \% of the air-dry weight of raw materials). 


\begin{tabular}{|c|c|c|c|c|c|c|c|}
\hline Species & 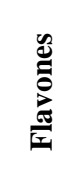 & 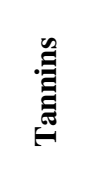 & 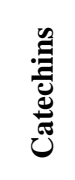 & $\stackrel{\mathscr{E}}{\mathscr{E}}$ & 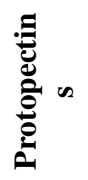 & 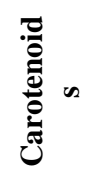 & 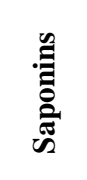 \\
\hline $\begin{array}{l}\text { M. didyma } \\
\text { Vegetation. } \\
1 \text { year of life, } 2019 .\end{array}$ & 3,55 & 20,54 & 0,18 & 1,84 & 8,14 & 94,36 & 8,72 \\
\hline $\begin{array}{l}\text { M. citriodora } \\
\text { Vegetation. } \\
1 \text { year of life, } 2019 .\end{array}$ & 4,26 & 20,65 & 0,17 & 1,84 & 9,39 & 96,88 & 12,75 \\
\hline $\begin{array}{l}\text { M. fistulosa } \\
\text { Vegetation. } \\
1 \text { year of life, } 2019 .\end{array}$ & 2,87 & 19,01 & 0,12 & 1,78 & 9,44 & 184,07 & 15,38 \\
\hline $\begin{array}{l}\text { M. media } \\
\text { Vegetation. } \\
1 \text { year of life, } 2019 .\end{array}$ & 2,25 & 13,39 & 0,20 & 1,26 & 12,22 & 87,88 & 9,61 \\
\hline $\begin{array}{l}\text { M. menthaifolia } \\
\text { Flowering. } \\
2 \text { years of life, } 2018 .\end{array}$ & 2,30 & 17,19 & 0,35 & 0,74 & 9,80 & 125,63 & 1,86 \\
\hline $\begin{array}{l}\text { M. menthaifolia } \\
\text { Flowering. } \\
3 \text { years of life, } 2019 .\end{array}$ & 3,90 & 14,68 & 0,26 & 0,97 & 8,62 & 102,73 & 7,18 \\
\hline
\end{tabular}

Acknowledgments: Work is carried out in frames of the projects of the state mission of the Central Siberian Botanical Garden of SB RAS № AAAA-A21-121011290025-2

\section{References}

1. S. Feskov, M. Shevchuk, Bulletin of GNBS 124 (2017)

2. G. Vysochina, Chemistry for sustainable development 2 (2020)

3. A. Nikitina, A. Aliev, S. Feshkov, N. Nikitina, Chemistry of plant raw materials 2 (2018)

4. T. Kukushkina, A. Zykov, L. Obukhova, Actual problems of creating new drugs of natural origin (2003)

5. V. Belikov, M. Schreiber, Pharmacy 1 (1970)

6. L. Fedoseeva, Chemistry of vegetable raw materials 2 (2005)

7. Methods of biochemical analysis of plants (Leninigrad, 1987)

8. Methods of biochemical analysis of plants. (L.: Publishing house of Leningrad State University, 1978)

9. V. Kriventsov, Proceedings of Nikit. Botan. Gardens 109 (1989)

10. A. Kiseleva, T. Volkhonskaya, V. Kiselev, Biologically active substances of medicinal plants of Southern Siberia (Novosibirsk, 1991)

11. O. Kotsupy, N. Stepantsova, G. Vysochina, A. Petruk, Irkutsk State University Bulletin. Series: Biology. Ecology 24 (2018) 